\title{
Sonication enhances quality and antioxidant activity of blueberry juice
}

\author{
Yu ZOU ${ }^{1 \star}$, Xiyan HOU ${ }^{1}$
}

\begin{abstract}
Effect of sonication on the blueberry juice was studied by evaluating the $\mathrm{pH}$, viscosity, electric conductivity, color, total sugars, soluble solids, polyphenol, anthocyanidin, and radical scavenging activities. There were not any remarkable $(p>0.05)$ change in $\mathrm{pH}$ and electric conductivity. However, viscosity and color of blueberry juice markedly $(p<0.05)$ enhanced with the extension of sonication time. Meanwhile, total sugars, soluble solids, polyphenol, and anthocyanidin were obviously enhanced $(p<0.05)$. Moreover, prominent increase $(p<0.05)$ was observed on DPPH, superoxide, and hydroxyl radicals scavenging activities of sonicated blueberry juice. The current results exhibited sonication effectively improved blueberry juice quality and enhanced its antioxidant activity.
\end{abstract}

Keywords: sonication; quality; radical scavenging activity; blueberry juice.

Practical Application: Sonication can be used potentially for juice processing and enhance quality and antioxidant activity of juice.

\section{Introduction}

Blueberry, a small fleshy berry, is one of the most popular and nutritious fruits. Blueberry and blueberry juice not only contain main dietary nutrients including minerals, sugars, and vitamins, but also are regarded as one of the most abundant and accessible sources of the bioactive components that are beneficial to the human health (Hwang et al., 2014; Seeram, 2008). There are some researches display that dietary intake of blueberry and its derived products can protect our body from various diseases including cancer, ageing, urinary disease, heart disease, memory loss, and vision problems (Pertuzatti et al., 2014; Shi et al., 2008).

In recent years, for purpose of meeting consumer demand of more safe, healthy, and nutritious foodstuff, many studies of food processing field have moved from the conventional thermal processing technology to the innovative non-thermal treatment technologies (Zou \& Jiang, 2016). Thermal processing of food product can lead to some adverse organoleptic and nutritional losses (Gómez et al., 2011). However, innovative emerging non-thermal treatment approaches can be used to enhance food quality and ensure its security without any damage or adverse impact to food nutrients (Caminiti et al., 2011).

Sonication is one of non-thermal treatment approaches, which may observably enhance food quality and avoid nutrient damage (Cheok et al., 2013). In the last few years, impact of sonication on raw juices from fruits and vegetables such as kasturi lime, cantaloupe melon, apple, orange, and carrot (Abid et al., 2013; Bhat et al., 2011; Fonteles et al., 2012; Jabbar et al., 2014; Tiwari et al., 2008) has been investigated and proved to an appropriate processing method of the juice. Sonication can effectively retain the most beneficial nutrients and decrease microbial load in the juice (Zou \& Jiang, 2016). Moreover, sonication can shorten processing time and reduce energy consumption (Abid et al., 2014). However, until now there is still little report available in literatures about impact of sonication on the processing of blueberry juice.

This research explored impact of sonication on physicochemical parameters of blueberry juices by evaluating the $\mathrm{pH}$, viscosity, electric conductivity, color, total sugars, soluble solids, polyphenol, and anthocyanidin. Moreover, the scavenging activities of sonicated blueberry juice on DPPH, superoxide, and hydroxyl radicals were investigated.

\section{Materials and methods}

\subsection{Materials}

Blueberry (Vaccinium uliginosum L.) was grown in Zhuanghe City (Liaoning, China) and harvested in August 2015. Fresh blueberry fruit was preserved at $-20^{\circ} \mathrm{C}$. DPPH and gallic acid were obtained from Sigma Chemicals Co., USA.

\subsection{Preparation and sonication treatment of blueberry juice}

Cleaned blueberry fruits were cracked using a BL25C46 electrical juice extractor (Midea, China). Then, solid particles were removed from crude juice by filtration. The conical flask containing the prepared juice sample was put into a KQ250-DB sonication cleaning bath (Kunshan, China) working at a sonication intensity of $0.5 \mathrm{~W} / \mathrm{cm}^{2}$ and a frequency of $40 \mathrm{kHz}$. Sonication treatment was performed in darkness for 20,40 , or $60 \mathrm{~min}$. Similarly, samples without sonication were served as control. 


\subsection{Measurement of $\mathrm{pH}$}

Measurement of $\mathrm{pH}$ was carried out with a FE20-FiveEasy $\mathrm{pH}$ meter (Mettler Toledo, Switzerland).

\subsection{Measurement of viscosity}

Measurement of viscosity was carried out with a DNJ-8S rotary viscometer (Jingmi, China) with S-4 spindle at $60 \mathrm{rpm}$.

\subsection{Measurement of electric conductivity}

Measurement of electric conductivity was carried out with a FE30-FiveEasy digital conductivity meter (Mettler Toledo, Switzerland).

\subsection{Measurement of color}

Measurement of color was carried out with a CR- 400 colorimeter (Minolta, Japan). The levels of $a^{\star}$ value represented visually from redness to greenness. The levels of $b^{\star}$ value represented visually from yellowness to blueness. The levels of $L^{*}$ value represented visually from whiteness or brightness to darkness.

\subsection{Measurement of total sugars}

The total sugars of juice sample were determined using phenol-sulfuric acid method (Zou \& Jiang, 2016). The screw cap tube containing $0.6 \mathrm{~mL}$ juice sample and $0.3 \mathrm{~mL}$ phenol solution was capped and blended. The sulfuric acid $(1.5 \mathrm{~mL})$ was directly added to the liquid surface in tube, followed by incubation at $20{ }^{\circ} \mathrm{C}$ for $0.5 \mathrm{~h}$. Then, optical density of reaction solution at $490 \mathrm{~nm}$ was determined in the UV-2600 spectrophotometer (Unico, USA) and the distilled water was used as blank.

\subsection{Measurement of soluble solids}

Measurement of soluble solids was carried out with a Master-20M hand held refractometer (Atago, Japan) and the results were expressed as ${ }^{\circ}$ Brix.

\subsection{Measurement of polyphenol}

Measurement of polyphenol was carried out according to Folin-Ciocalteu colorimetric method of Singleton et al. (1999). Briefly, $2 \mathrm{~mL}$ juice sample was adequately blended with $10 \%$ sodium carbonate solution $(5 \mathrm{~mL})$ and $10 \%$ Folin-Ciocalteu reagent $(10 \mathrm{~mL})$. Then, mixture was kept at $20{ }^{\circ} \mathrm{C}$ for $2 \mathrm{~h}$ in darkness. Optical density of the reaction solution at $765 \mathrm{~nm}$ was determined and the result was presented as $\mathrm{mg} / \mathrm{L}$ of gallic acid equivalents (GAE).

\subsection{Measurement of anthocyanidin}

Measurement of anthocyanidin was carried out using Lambert-Beer law (Fan et al., 2008). Briefly, $0.5 \mathrm{~mL}$ juice sample was adequately blended with $4.5 \mathrm{~mL}$ acid-ethanol solution $(1.5 \mathrm{M} \mathrm{HCl})$ and then optical density of mixture at $530 \mathrm{~nm}$ was accurately detected. Equation 1 was employed to calculate anthocyanins content.
$Y(m g / L)=X \times K_{1} / K_{2}$

where $Y$ was the anthocyanins content, $X$ was optical density of mixture, $K_{1}$ was dilution factor of sample solution, and $K_{2}$ was the molar absorptive factor (98.2) for acid-ethanol solvent.

\subsection{Measurement of DPPH radicals scavenging activities}

Measurement of DPPH radicals scavenging activities was carried out according to method of Tu et al. (2009). Briefly, $4 \mathrm{~mL}$ sample solution was adequately blended with $4 \mathrm{~mL} \mathrm{DPPH}$ ethanol solution $(0.2 \mathrm{mM})$, and then the mixture was kept away from light for $1 \mathrm{~h}$. Optical density of mixture at $517 \mathrm{~nm}$ was detected against blank (ethanol solution). Equation 2 was employed to calculate DPPH radicals scavenging activities.

$Y(\%)=\left[1-\left(X_{1}-X_{2}\right) / X_{3}\right] \times 100$

where $Y$ were DPPH radicals scavenging activity, $X_{1}$ was optical density of reaction mixture, $X_{2}$ was optical density of sample solution, and $X_{3}$ was optical density of DPPH solution.

\subsection{Measurement of superoxide radicals scavenging activities}

Measurement of superoxide radicals scavenging activities was carried out according to method of Martinez et al. (2001). In short, sample solution $(1 \mathrm{~mL})$ was adequately blended with mixture solution $(3 \mathrm{~mL})$ containing methionine $(13 \mathrm{mM})$, EDTA $(100 \mu \mathrm{M})$, phosphate buffer (50 mM, pH 7.8), nitroblue tetrazolium $(75 \mu \mathrm{M})$, and riboflavin $(2 \mu \mathrm{M})$. After $15 \mathrm{~min}$ light treatment, optical density of reaction mixture at $560 \mathrm{~nm}$ was detected. Similarly, reaction solution kept away from light was used as blank. The distilled water was used to replace the sample as control. Equation 3 was employed to calculate superoxide radicals scavenging activities.

$Y(\%)=\left(1-X_{1} / X_{2}\right) \times 100$

where $Y$ was superoxide radicals scavenging activity, $X_{1}$ was optical density of sample solution, and $X_{2}$ was optical density of control.

\subsection{Measurement of hydroxyl radicals scavenging activities}

Measurement of superoxide radicals scavenging activities was carried out according to method of Zou et al. (2015). Sample solution $(1 \mathrm{~mL})$ was adequately blended with mixture solution (3 mL) containing ferric trichloride $(100 \mu \mathrm{M})$, phosphate buffer (20 mM, pH 7.4), $\mathrm{H}_{2} \mathrm{O}_{2}(1 \mathrm{mM})$, deoxyribose (60 mM), and EDTA $(100 \mu \mathrm{M})$. Mixture was kept at $37^{\circ} \mathrm{C}$ for $40 \mathrm{~min}$, and then blended with $20 \% \mathrm{HCl}(1 \mathrm{~mL})$ and $1 \%$ thiobarbituric acid $(1 \mathrm{~mL})$. The reaction was terminated by incubation in the boiling water for $20 \mathrm{~min}$. Optical density of reaction solution at $532 \mathrm{~nm}$ was detected and distilled water was used to replace the sample as control. Equation 4 was employed to calculate hydroxyl radicals scavenging activities.

$Y(\%)=\left(1-X_{1} / X_{2}\right) \times 100$ 
where $Y$ was hydroxyl radicals scavenging activity, $X_{1}$ was optical density of sample solution, and $X_{2}$ was optical density of control.

\subsection{Statistical analysis}

The data obtained from the study were indicated as means \pm standard deviation. The significance difference $(p<0.05)$ among means was measured with Fisher's F-test.

\section{Results and discussion}

\subsection{Impact of sonication on $p H$, viscosity, electric conductivity, and color}

It was observed from Table 1 that during sonication there was no prominent $(p>0.05)$ variation in $\mathrm{pH}$ of blueberry juice. However, there was an obvious $(p<0.05)$ enhancement in viscosity of sonicated blueberry juice compared to control. It is possibly caused by sonication which accelerated macromolecules, especially sugar compounds, to permeate cell membranes and go into solution. In the colloidal solution, the sugar concentration was connected with the viscosity (Suárez-Jacobo et al., 2011). Therefore, the release of sugar compounds caused by sonication resulted in the increase in viscosity of blueberry juice.

As shown in Table 1, the negligible enhancement was found in electric conductivity of blueberry juices treated with sonication. Generally, juices could conduct electricity due to the existence of water, minerals, and vitamins as conductors (Zou \& Jiang, 2016). Sonication facilitated release of mineral substance and vitamins came from colloidal particles or cells in blueberry fruit and enhanced their contents in the colloidal solution. Thus, there was a negligible enhancement in electric conductivity of blueberry juices treated with sonication.

Impact of sonication on color of blueberry juice is presented in Table 2. It was observed sonication observably $(p<0.05)$ influence color attributes $\left(a^{*}, b^{*}\right.$ and $\left.L^{*}\right)$. With the extension of sonication time, color values gradually enhanced. Zou \& Jiang (2016) investigated influence of sonication on color of carrot juice and observed the variation of color values during sonication.

Table 1. Influence of sonication on $\mathrm{pH}$, viscosity, and electric conductivity.

\begin{tabular}{cccc}
\hline $\begin{array}{c}\text { Sonication } \\
\text { time } \\
(\mathrm{min})\end{array}$ & $\mathrm{pH}$ & $\begin{array}{c}\text { Viscosity } \\
(\mathrm{mPa} \cdot \mathrm{s})\end{array}$ & $\begin{array}{c}\text { Electric } \\
\text { conductivity } \\
(\mathrm{ms} / \mathrm{cm})\end{array}$ \\
\hline 0 & $3.12 \pm 0.02^{\mathrm{a}}$ & $2.28 \pm 0.04^{\mathrm{c}}$ & $10.65 \pm 0.06^{\mathrm{a}}$ \\
20 & $3.13 \pm 0.03^{\mathrm{a}}$ & $2.41 \pm 0.05^{\mathrm{b}}$ & $10.73 \pm 0.05^{\mathrm{a}}$ \\
40 & $3.11 \pm 0.03^{\mathrm{a}}$ & $2.53 \pm 0.08^{\mathrm{a}}$ & $10.71 \pm 0.07^{\mathrm{a}}$ \\
60 & $3.09 \pm 0.01^{\mathrm{a}}$ & $2.64 \pm 0.08^{\mathrm{a}}$ & $10.74 \pm 0.04^{\mathrm{a}}$ \\
\hline
\end{tabular}

Means in same column with different lower-case letter are markedly different at $p<0.05$.

Table 2. Influence of sonication on color attributes.

\begin{tabular}{cccc}
\hline \multirow{2}{*}{$\begin{array}{c}\text { Sonication time } \\
(\mathrm{min})\end{array}$} & $a^{*}$ & $b^{*}$ & $L^{*}$ \\
\cline { 2 - 4 } & $0.91 \pm 0.05^{\mathrm{b}}$ & $1.87 \pm 0.01^{\mathrm{c}}$ & $22.96 \pm 0.04^{\mathrm{b}}$ \\
0 & $0.98 \pm 0.02^{\mathrm{b}}$ & $1.98 \pm 0.02^{\mathrm{b}}$ & $23.06 \pm 0.03^{\mathrm{a}}$ \\
40 & $1.08 \pm 0.03^{\mathrm{a}}$ & $2.09 \pm 0.02^{\mathrm{a}}$ & $23.08 \pm 0.02^{\mathrm{a}}$ \\
60 & $1.12 \pm 0.04^{\mathrm{a}}$ & $2.13 \pm 0.04^{\mathrm{a}}$ & $23.09 \pm 0.04^{\mathrm{a}}$ \\
\hline
\end{tabular}

Means in same column with different lower-case letter are markedly different at $p<0.05$.
It was well-known that pigment could be affected by cavitations produced from sonication (Zou et al., 2010). At present study, the variation of color values in sonicated blueberry juice was connected with pigment content. On the one hand, sonication could accelerate release of pigment from the blueberry tissues. On the other hand, sonication might damage pigment structure and affect its light absorption.

\subsection{Impact of sonication on total sugars, soluble solids, polyphenol, and anthocyanidin}

The content of carbohydrates was main quality parameter of blueberry juice which markedly influenced the organoleptic properties of juice. As shown in Table 3, experimental result exhibited sonication led to remarkable $(p<0.05)$ changes in total sugars and soluble solids. Total sugars enhanced from 34.1 to $35.0 \mathrm{~g} / \mathrm{L}$ and soluble solids enhanced from 5.0 to $5.3^{\circ} \mathrm{Brix}$, respectively. The enhancement of total sugars and soluble solids was possibly due to the enhancement in extraction efficacy. Sonication destroyed fruit tissues and cell walls, resulting in more water might enter into fruit cells and more soluble solids might across cell membranes (Zou et al., 2010).

A large quantity of phenolic compounds and anthocyanidin s exist in fresh fruit and juice. These compounds are surprisingly beneficial to the sensory properties and antioxidant capacity of juice products (Khanizadeh et al., 2008). Moreover, the color of anthocyanins may enhance the aesthetic perception of juice and make it more attractive and desirable for consumers. As shown in Table 3, results showed a remarkable $(p<0.05)$ enhancement in polyphenol and anthocyanidin of blueberry juice treated with sonication for $40 \mathrm{~min}$ as compared with juices sonicated for $20 \mathrm{~min}$ and the control. Abid et al. (2013) observed the identical result that sonication could enhance total phenols of apple juice. These experimental results revealed that sonication enhanced bioactive compounds content in the juice.

\subsection{Impact of sonication on radical scavenging activity}

Radicals scavenging activities in food were very important to stay the health of consumers because free radicals could accelerate lipids oxidation and induce serious tissue damage (Peksel et al., 2010). Determination of DPPH radical was simple and effective method to assess antioxidant ability of the food. As shown in Table 4, DPPH radicals scavenging activities respectively reached $53 \%, 63 \%, 70 \%$, and $73 \%$ in samples sonicated for $0,20,40$, and $60 \mathrm{~min}$. The experimental result showed that the scavenging activities of blueberry juice on DPPH

Table 3. Influence of sonication on total sugars, soluble solids, polyphenol, and anthocyanidin.

\begin{tabular}{ccccc}
\hline $\begin{array}{c}\text { Sonication } \\
\text { time } \\
(\mathrm{min})\end{array}$ & $\begin{array}{c}\text { Total sugars } \\
(\mathrm{g} / \mathrm{L})\end{array}$ & $\begin{array}{c}\text { Soluble } \\
\text { solids } \\
\left({ }^{\circ} \text { Brix }\right)\end{array}$ & $\begin{array}{c}\text { Polyphenol } \\
(\text { GAT, mg/L) }\end{array}$ & $\begin{array}{c}\text { Anthocyanidin } \\
(\mathrm{mg} / \mathrm{L})\end{array}$ \\
\hline 0 & $34.1 \pm 0.1^{\mathrm{c}}$ & $5.0 \pm 0.1^{\mathrm{d}}$ & $528 \pm 9^{\mathrm{c}}$ & $228 \pm 8^{\mathrm{c}}$ \\
20 & $34.6 \pm 0.1^{\mathrm{b}}$ & $5.1 \pm 0.1^{\mathrm{c}}$ & $568 \pm 7^{\mathrm{b}}$ & $247 \pm 8^{\mathrm{b}}$ \\
40 & $34.7 \pm 0.1^{\mathrm{b}}$ & $5.2 \pm 0.1^{\mathrm{b}}$ & $589 \pm 7^{\mathrm{a}}$ & $266 \pm 6^{\mathrm{a}}$ \\
60 & $35.0 \pm 0.1^{\mathrm{a}}$ & $5.3 \pm 0.1^{\mathrm{a}}$ & $585 \pm 8^{\mathrm{a}}$ & $266 \pm 5^{\mathrm{a}}$ \\
\hline
\end{tabular}

Means in same column with different lower-case letter are markedly different at $p<0.05$. 
Table 4. Influence of sonication on radical scavenging activity.

\begin{tabular}{cccc}
\hline \multirow{2}{*}{$\begin{array}{c}\text { Sonication time } \\
(\text { min })\end{array}$} & \multicolumn{3}{c}{ Scavenging activity (\%) } \\
\cline { 2 - 4 } & DPPH radical & $\begin{array}{c}\text { superoxide } \\
\text { radical }\end{array}$ & hydroxyl radical \\
\hline 0 & $53 \pm 3^{\mathrm{c}}$ & $41 \pm 2^{\mathrm{d}}$ & $45 \pm 2^{\mathrm{c}}$ \\
20 & $63 \pm 2^{\mathrm{b}}$ & $48 \pm 3^{\mathrm{c}}$ & $55 \pm 3^{\mathrm{b}}$ \\
40 & $70 \pm 3^{\mathrm{a}}$ & $56 \pm 2^{\mathrm{b}}$ & $63 \pm 3^{\mathrm{a}}$ \\
60 & $73 \pm 2^{\mathrm{a}}$ & $62 \pm 2^{\mathrm{a}}$ & $65 \pm 2^{\mathrm{a}}$ \\
\hline
\end{tabular}

Means in same column with different lower-case letter are markedly different at $p<0.05$.

radicals observably $(p<0.05)$ increased with the extension of sonication time.

The superoxide could combine with other radicals, such as hydroxyl and nitric oxide, to form stronger reactive species and possess greater oxidative ability (Peksel et al., 2010). Table 4 exhibited that scavenging activities of superoxide radicals increased from $41 \%$ up to $48 \%, 56 \%$, and $62 \%$ in blueberry juice sonicated for $0,20,40$, and $60 \mathrm{~min}$, respectively. The experimental results indicated that sonication markedly $(p<0.05)$ enhanced superoxide radicals scavenging activities of blueberry juice.

Hydroxyl radical was one of the strongest reactive radicals, which induced serious cell injury and caused senescence, tumour and other severe diseases (Zou et al., 2015). It was observed that there was a prominent $(p<0.05)$ increase in hydroxyl radicals scavenging activities of blueberry juice sonicated for $0,20,40$, and $60 \mathrm{~min}$ ranged from $45 \%$ to $55 \%, 63 \%$, and $65 \%$ (Table 4). A similar result was obtained by Zhang et al. (2015) who found, with the extension of sonication time, the scavenging abilities of Maillard reaction products on oxygen radical also increased.

The increase in radicals scavenging activity was possibly ascribed to the enhancement in polyphenolic compounds and anthocyanins in blueberry juice during sonication (Abid et al., 2013). The longer sonication time was, the more antioxidants could enter solution and the more free radicals could be scavenged. Therefore, sonication plays a main role in improving the antioxidant activity of blueberry juice. It is one of the most important advantages of sonication.

\section{Conclusions}

Influence of sonication on the quality and radicals scavenging activities of blueberry juice was studied. There was not obvious $(p>0.05)$ variation in $\mathrm{pH}$ and electric conductivity. With extension of sonication time, viscosity and color observably $(p<0.05)$ enhanced. Total sugars, soluble solids, polyphenol, and anthocyanidin were markedly $(p<0.05)$ improved during sonication. Scavenging activities of sonicated blueberry juice on DPPH, superoxide and hydroxyl radicals significantly $(p<0.05)$ increased. The present results indicated that sonication could be successfully applied to blueberry juice processing and enhanced its quality and antioxidant activity.

\section{Acknowledgements}

This work was supported by Program for Liaoning Excellent Talents in University (No. LJQ2015031) and Fundamental Research Funds for the Central Universities (No. DC201501080).

\section{References}

Abid, M., Jabbar, S., Wu, T., Hashim, M. M., Hu, B., Lei, S., \& Zeng, X. (2014). Sonication enhances polyphenolic compounds, sugars, carotenoids and mineral elements of apple juice. Ultrasonics Sonochemistry, 21(1), 93-97. PMid:23835397. http://dx.doi. org/10.1016/j.ultsonch.2013.06.002.

Abid, M., Jabbar, S., Wu, T., Hashim, M. M., Hu, B., Lei, S., Zhang, X., \& Zeng, X. (2013). Effect of ultrasound on different quality parameters of apple juice. Ultrasonics Sonochemistry, 20(5), 1182-1187. PMid:23522904. http://dx.doi.org/10.1016/j.ultsonch.2013.02.010.

Bhat, R., Kamaruddin, N. S., Min-Tze, L., \& Karim, A. A. (2011). Sonication improves kasturi lime (Citrus microcarpa) juice quality. Ultrasonics Sonochemistry, 18(6), 1295-1300. PMid:21550834. http:// dx.doi.org/10.1016/j.ultsonch.2011.04.002.

Caminiti, I. M., Noci, F., Muñoz, A., Whyte, P., Morgan, D. J., Cronin, D. A., \& Lyng, J. G. (2011). Impact of selected combinations of non-thermal processing technologies on the quality of an apple and cranberry juice blend. Food Chemistry, 124(4), 1387-1392. http:// dx.doi.org/10.1016/j.foodchem.2010.07.096.

Cheok, C. Y., Chin, N. L., Yusof, Y. A., Talib, R. A., \& Law, C. L. (2013). Optimization of total monomeric anthocyanin (TMA) and total phenolic content (TPC) extractions from mangosteen (Garcinia mangostana Linn.) hull using ultrasonic treatments. Industrial Crops and Products, 50, 1-7. http://dx.doi.org/10.1016/j.indcrop.2013.07.024.

Fan, G., Han, Y., Gu, Z., \& Chen, D. (2008). Optimizing conditions for anthocyanins extraction from purple sweet potato using response surface methodology (RSM). LWT - Food Science and Technology (Campinas.), 41(1), 155-160. http://dx.doi.org/10.1016/j.lwt.2007.01.019.

Fonteles, T. V., Costa, M. G. M., Jesus, A. L. T., Miranda, M. R. A., Fernandes, F. A. N., \& Rodrigues, S. (2012). Power ultrasound processing of cantaloupe melon juice: Effects on quality parameters. Food Research International, 48(1), 41-48. http://dx.doi.org/10.1016/j. foodres.2012.02.013.

Gómez, P. L., Welti-Chanes, J., \& Alzamora, S. M. (2011). Hurdle technology in fruit processing. Annual Review of Food Science and Technology, 2(1), 447-465. PMid:22129391. http://dx.doi.org/10.1146/ annurev-food-022510-133619.

Hwang, S. J., Yoon, W. B., Lee, O. H., Cha, S. J., \& Kim, J. D. (2014). Radical-scavenging-linked antioxidant activities of extracts from black chokeberry and blueberry cultivated in Korea. Food Chemistry, 146, 71-77. PMid:24176315. http://dx.doi.org/10.1016/j. foodchem.2013.09.035.

Jabbar, S., Abid, M., Hu, B., Wu, T., Hashim, M. M., Lei, S., Zhang, X., \& Zeng, X. (2014). Quality of carrot juice as influenced by blanching and sonication treatments. LWT - Food Science and Technology (Campinas.), 55(1), 16-21. http://dx.doi.org/10.1016/j.lwt.2013.09.007.

Khanizadeh, S., Tsao, R., Rekika, D., Yang, R., Charles, M. T., \& Vasantha Rupasinghe, H. P. (2008). Polyphenol composition and total antioxidant capacity of selected apple genotypes for processing. Journal of Food Composition and Analysis, 21(5), 396-401. http:// dx.doi.org/10.1016/j.jfca.2008.03.004.

Martinez, C. A., Loureiro, M. E., Oliva, M. A., \& Maestri, M. (2001). Differential responses of superoxide dismutase in freezing resistant Solanum curtilobum and freezing sensitive Solanum tuberosum subjected to oxidative and water stress. Plant Science, 160(3), 505-515. PMid:11166438. http://dx.doi.org/10.1016/S0168-9452(00)00418-0.

Peksel, A., Arisan-Atac, I., \& Yanardag, R. (2010). Evaluation of antioxidant and antiacetylcholinesterase activities of the extracts of Pistacia atlantica desf. leaves. Journal of Food Biochemistry, 34(3), 451-476. http://dx.doi.org/10.1111/j.1745-4514.2009.00290.x. 
Pertuzatti, P. B., Barcia, M. T., Rodrigues, D., Cruz, P. N., HermosínGutiérrez, I., Smith, R., \& Godoy, H. T. (2014). Antioxidant activity of hydrophilic and lipophilic extracts of Brazilian blueberries. Food Chemistry, 164, 81-88. PMid:24996309. http://dx.doi.org/10.1016/j. foodchem.2014.04.114.

Seeram, N. P. (2008). Berry fruits: compositional elements, biochemical activities, and the impact of their intake on human health, performance, and disease. Journal of Agricultural and Food Chemistry, 56(3), 627629. PMid:18211023. http://dx.doi.org/10.1021/jf071988k.

Shi, J., Pan, Z., McHugh, T. H., Wood, D., Hirschberg, E., \& Olson, D. (2008). Drying and quality characteristics of fresh and sugar-infused blueberries dried with infrared radiation heating. LWT - Food Science and Technology (Campinas.), 41(10), 1962-1972. http:// dx.doi.org/10.1016/ j.lwt.2008.01.003.

Singleton, V. L., Orthofer, R., \& Lamuela-Raventós, R. M. (1999). Analysis of total phenols and other oxidation substrates and antioxidant by means of Foline-Ciocalteu reagent. Methods in Enzymology, 299, 153-178. http://dx.doi.org/10.1016/S0076-6879(99)99017-1.

Suárez-Jacobo, A., Rüfer, C. E., Gervilla, R., Guamis, B., Roig-Sagués, A. X., \& Saldo, J. (2011). Influence of ultra-high pressure homogenisation on antioxidant capacity, polyphenol and vitamin content of clear apple juice. Food Chemistry, 127(2), 447-454. PMid:23140685. http:// dx.doi.org/10.1016/j.foodchem.2010.12.152.

Tiwari, B. K., Muthukumarappan, K., O’Donnell, C. P., \& Cullen, P. J. (2008). Effects of sonication on the kinetics of orange Juice quality parameters. Journal of Agricultural and Food Chemistry, 56(7), 2423-2428. PMid:18321054. http://dx.doi.org/10.1021/jf073503y.

Tu, Y., Sun, Y., Tian, Y., Xie, M., \& Chen, J. (2009). Physicochemical characterisation and antioxidant activity of melanin from the muscles of Taihe Black-bone silky fowl (Gallus gallus domesticus Brisson). Food Chemistry, 114(4), 1345-1350. http://dx.doi.org/10.1016/j. foodchem.2008.11.015.

Zhang, H., Yang, J., \& Zhao, Y. (2015). High intensity ultrasound assisted heating to improve solubility, antioxidant and antibacterial properties of chitosan-fructose Maillard reaction products. $L W T$ Food Science and Technology (Campinas.), 60(1), 253-262. http:// dx.doi.org/10.1016/ j.lwt.2014.07.050.

Zou, Y., Jiang, A., \& Tian, M. (2015). Extraction optimization of antioxidant polysaccharides from Auricularia auricula fruiting bodies. Food Science and Technology (Campinas.), 35(3), 428-433. http://dx.doi.org/10.1590/1678-457X.6712.

Zou, Y., \& Jiang, A. (2016). Effect of ultrasound treatment on quality and microbial load of carrot juice. Food Science and Technology (Campinas.), 36(1), 111-115. http://dx.doi.org/10.1590/1678-457X.0061.

Zou, Y., Xie, C., Fan, G., Gu, Z., \& Han, Y. (2010). Optimization of ultrasound-assisted extraction of melanin from Auricularia auricula fruit bodies. Innovative Food Science \& Emerging Technologies, 11(4), 611-615. http://dx.doi.org/10.1016/j.ifset.2010.07.002. 